\title{
Creeping Bluestem Compared with Four Other Native Range Grasses
}

\section{ROBERT D. ROUSH AND LEWIS L. YARLETT}

Highlight: Creeping bluestem (Andropogon stolonifer [Nash] Hitchc.), an important rhizomatous perennial native bluestem of Florida and southeast Georgia, was compared under five use-management schemes with four other important native range grasses common to the same region. The creeping bluestem was found to consistently outyield the other grasses throughout all the use-management plans under which they were compared. Three systems of management found feasible for the utilization of and continuing stand development of creeping bluestem were found to be: (1) periodic spring, summer, and autumn forage removal to $50 \%$ of leaf height plus complete forage utilization in the wintertime; (2) autumn forage removal during full bloom stage to $50 \%$ of leaf height coupled with full forage utilization in wintertime; and (3) full forage utilization in the wintertime.

Five of the more common and potentially more important native range grasses of Florida were selected for management studies to determine the optimum rate for seasonal utilization and the relative forage productivity of the respective grasses. Four bluestem and one threeawn species comprised the observational group. The particular grasses studied were chalky bluestem (Andropogon capillipes Nash), South Florida bluestem (A. rhizomatous Swallen), creeping bluestem ( $A$. stolonifer (Nash) Hitchc.), broomsedge (A. virginicus L.), and Florida threeawn (Aristida rhizomophora Swallen) as described by Small (1903) or Hitchcock (1950).

All of the above grasses, except the South Florida bluestem, are widely distributed over a broad range of soils throughout much of Florida. South Florida bluestem is an excellent sodforming grass but is limited in natural distribution to widely scattered portions of South Florida. Both the South Florida and the creeping bluestems are rhizomatous and have perenniated over a period of years in plantings made at the Soil Conservation Service (SCS)-

The authors are Plant Materials Center manager, Soil Conservation Service, Brooksville, Florida, and formerly state resource conservation Service, U. S. Department of Agriculture, Gainesville, Florida, presently regional range conservationist, Western Region, Soil Conserv. Serv., U.S. Dep. of Agr., Portland, Oregon. Manuscript received January 19, 1972.
University of Georgia Plant Materials Center, Americus, Ga., and at the SCS-Plant Materials Centers at Coffeeville, Miss., and Arcadia and Brooksville, Fla. Florida threeawn is also rhizomatous and perennial but with a much slower rate of lateral spread than either of the bluestem species. Both the chalky bluestem and the broomsedge are perennial bunch-type grasses.

All of the species listed are used by grazing livestock. Creeping bluestem, South Florida bluestem, and chalky bluestem are readily sought out and grazed. Florida threeawn is moderately utilized and broomsedge is least preferred of these grasses. Observations indicated that both creeping and South Florida bluestems are usually low in vigor on heavily grazed ranges and are often suppressed by crown canopies of brush and trees. Chalky bluestem increases rapidly on mechanically disturbed areas but is readily grazed out. Broomsedge increases markedly in old fields, in mechanically disturbed areas, and on heavily grazed rangelands of Florida.

Sites of adaptation for the five species are generally similar to those as described for creeping bluestem (Yarlett and Roush, 1970). Creeping bluestem usually grows best on somewhat poorly to poorly drained, acid, and moderately alkaline soils but is occasionally found on welldrained soils. South Florida bluestem develops most readily on moderately alkaline, somewhat poorly to poorly drained soils. Florida threeawn and broomsedge both have a wide range of adaptability to acid soils. Chalky bluestem grows best on somewhat poorly to poorly drained, moderately acid soils.

To determine the management means by which the more desirable sod-forming, productive, and more highly palatable grasses could be developed and maintained, we conducted a series of tests which included the above-listed grasses.

\section{Procedure}

All species studied were established by transplanting individual plants or comparable-sized sod chunks. The five grasses were planted into rod-length rows, each species replicated five times. South Florida bluestem and Florida threeawn were planted December 19, 1962; creeping bluestem, January 8, 1963; chalky bluestem, February 1, 1963; and broomsedge, March 1, 1963. The young plants were watered during the establishment period until the summer rains started in 1963. No further irrigation was applied for the duration of the observational period. During 1963 the plants were allowed to develop without the removal of top materials.

Seasonal fertilization included the application of $8-8-8$ at $800 \mathrm{lb}$./acre plus 33-0-0 fertilizer at $100 \mathrm{lb}$./acre. One-half the $8-8-8$ was applied during the period from February 15 to 28 , and the second half was applied September 1 to 15 . The 8-8-8 fertilizer was fortificd with minor elements: copper sulfate-1\%; ferrous, manganese and zinc sulfates plus a borate $-1 / 2 \%$ each. No minor element supplements were added to the ammonium nitrate fertilizer. The 33-0-0 fertilizer was applied annually during the period from July 1 to 15 . Beginning with 1964 fertilization was discontinued on the east one-half of each rod row. Application of fertilizer was continued at the same rates, analyses, and time intervals on the west one-half of each rod row planting.

Top growth for the previous year was removed on March 2, 1964, from each of the 25 rows by mowing to a height of 4 inches above ground level. These forage materials were discarded. Yield determinations were made throughout 1964 1965 , and 1966 for each of the respective five-rod rows of each accession in the observational planting according to the following schedule:

Treatment I - Forage cut to 4-inch height each time the plants grew to an 8-inch height.

Treatment II - 50\% of current growth materials removed in accordance with leaf height measurement each April 1, June 
Table 1. Forage yields (tons/acre) from 5 selected range grasses subjected to 5 levels of utilization treatments, harvested during the years 1964 through 1966. (From plantings of the Soil Conservation Service Plant Materials Center, Arcadia, Florida.)

\begin{tabular}{llllll}
\hline & \multicolumn{5}{c}{ Treatment } \\
\cline { 2 - 6 } Grasses observed & I & II & III & IV & V \\
\hline South Florida bluestem & $1.69^{1}$ & 4.69 & 4.80 & 4.05 & 3.74 \\
Florida threeawn & 2.62 & 3.40 & 4.33 & 1.44 & 0.64 \\
Creeping bluestem & 5.38 & 9.60 & 8.89 & 7.50 & 7.41 \\
Chalky bluestem & 0.34 & 0.37 & 0.65 & 0.63 & 0.22 \\
Broomsedge & 1.08 & 1.03 & 1.53 & 0.77 & 1.16 \\
\hline
\end{tabular}

${ }^{1}$ The data represent the averages of the annually summarized weights of freshly cut materials. They are a composite of the yields from both the fertilized and nonfertilized portions of the individual rows as no attempt was made to harvest and determine the yields separately.
Table 3. Relative vigor for surviving plants of five selected range grasses under fertilized and unfertilized conditions following subjection to five levels of utilization treatment for 3 years.

\begin{tabular}{lccccc}
\hline & \multicolumn{5}{c}{ Treatment } \\
\cline { 2 - 6 } Grasses observed & I & II & III & IV & V \\
\hline Chalky bluestem & $1: 0^{1}$ & $2: 1$ & $2: 2$ & $1: 1$ & $1: 1$ \\
South Florida bluestem & $2: 2$ & $3+: 3+$ & $3: 3$ & $3+: 3+$ & $3+: 3+$ \\
Creeping bluestem & $2: 1$ & $4: 4$ & $2: 2+$ & $4+: 5$ & $5: 5+$ \\
Broomsedge & $1: 1$ & $2: 1$ & $1: 2$ & $1: 1$ & $2: 1$ \\
Threeawn & $1: 1$ & $2-: 2$ & $2-: 2-$ & $2: 2+$ & $2-: 2$ \\
\hline
\end{tabular}

1Ratings: Dead - 0; Weak - 1; Fair - 2; Good - 3; Excellent 4; Superior - 5. Plus or minus signs modify ratings. Unfertilized - left; fertilized - right.

\section{5, and September 1.}

Treatment III - $75 \%$ of current growth materials removed in accordance with leaf height measurement each April 1 , June 15, and September 1.

Treatment IV - 50\% of current growth materials removed at full bloom period (at point equivalent to one-half of leaf height).

Treatment $V$ - All growth removed to 4-inch height when plants were at full maturity and with fully mature culm growth (clippings made annually during January 1-15 period).

The single row of each species which was cut only once, annually, was considered to be the check row, as this manner of treatment provided the least frequent annual usage, the greatest continuous period of usage deferment, and full utilization of the top growth of the previous season during the dormant or semidormant period. The other four rows of each species were also uniformly clipped to 4-inch height during the period from January 1 to 15 irrespective of other seasonal removal of forage. The January 1 to 15 dormant season clipping represented the final clipping and removal of each previous year's growth. The yield data thus obtained was included respectively in summarizing the forage production of the previous year for the individual rod row planting.

\section{Results and Discussion}

Of the five grasses tested, creeping

bluestem consistently outyielded the other four grasses. This fact is verified by direct comparison of the average annual forage yields produced by the various grasses within specific treatment schemes shown in Table 1. South Florida bluestem and Florida threeawn, respectively, were second and third in comparative production.

Frequent cutting of all the test grasses to a 4-inch height resulted, generally, in the greatest reduction of forage yields and plant survival. Three times yearly removal of $75 \%$ of the top materials produced, within species, the highest yield weights of fresh forage for each of the grasses except the creeping bluestem. Three times yearly removal of $50 \%$ of the top materials allowed the greatest average annual fresh weight forage production for the creeping bluestem. The second highest average yield of fresh forage was also produced by the creeping bluestem with 75\% removal of top materials. In this latter instance, although the plant survival remained at $100 \%$ (Table 2), the creeping bluestem overall plant vigor (Table 3) was reduced by removal of $75 \%$ of top materials as compared to that obtained by this same grass with removal of $50 \%$ of the top materials (Fig. 1). For the grasses studied, the $75 \%$ removal of top materials (by leaf height measurement) closely approximates the range management concept of 'take half-leave half' (by weight measurement).

Creeping bluestem harvested with 50\%

Table 2. Survival percentages of five selected range grasses under fertilized and unfertilized conditions following subjection to five levels of utilization treatment for three years.

\begin{tabular}{lccccc}
\hline & \multicolumn{5}{c}{ Treatment } \\
\cline { 2 - 6 } Grasses observed & I & II & III & IV & V \\
\hline Chalky bluestem & $17: 0^{1}$ & $42: 8$ & $33: 8$ & $50: 25$ & $25: 33$ \\
South Florida bluestem & $100: 8$ & $100: 100$ & $100: 100$ & $100: 100$ & $100: 100$ \\
Creeping bluestem & $100: 100$ & $100: 100$ & $100: 100$ & $100: 100$ & $100: 100$ \\
Broomsedge & $42: 33$ & $33: 17$ & $8: 42$ & $33: 17$ & $58: 25$ \\
Threeawn & $100: 100$ & $100: 75$ & $100: 92$ & $83: 83$ & $100: 33$ \\
\hline
\end{tabular}

${ }^{1}$ Unfertilized - left; fertilized - right. removal of top materials at full bloom stage plus full utilization of the forage in wintertime and that subjected solely to full wintertime utilization show lower average yield values. These seeming reductions in forage yield are offset by their correspondingly higher dry matter content. Harvest experience has shown these materials to contain 33 to $67 \%$ of essentially airdry leaves and stems. Yields for the grasses observed in this series of tests may be contrasted with some of the same and similar range species as previously reported by Yarlett et al. (1970).

South Florida bluestem was the second most productive grass. It is somewhat less persistent and less hardy under use than creeping bluestem (Fig. 2). Response to treatment was essentially in the same order as for creeping bluestem, but it was somewhat more severely affected by the most intense clipping rate.

Throughout the period of herbage removal, creeping bluestem continued development showing plant vigor ratings from weak to fair under the most severe usage to superior under the least frequent usage. Plant height and basal spread progressed inversely with severity of use. Response of the South Florida bluestem was similar but to a lesser degree. The low survival for South Florida bluestem under fertilization at heavy usage is not understood (Table 2). A similar weakness in the general vigor of the creeping bluestem grown under fertilization is not explainable when contrasted with unfertilized plants grown in the same row (Table 3).

Florida threeawn ranked third in productive capacity (Fig. 3). Its greatest production of fresh forage was achieved under $75 \%$ top removal.

Broomsedge forage yield values appear to have been affected least by harvesting method, although it should be remembered that some of the materials harvested were of considcrably advanced maturity (Fig. 4). The survival of 


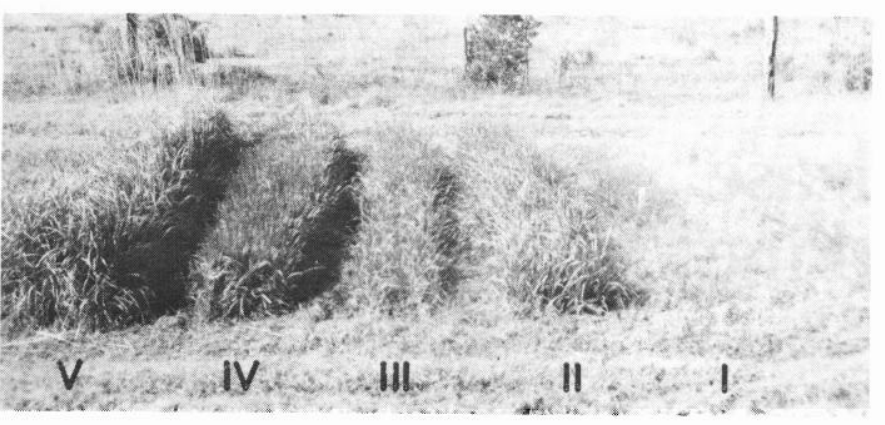

Fig. 1. Creeping bluestem was seriously suppressed by treatment in treatment I and moderately so in treatment III. Treatments II, IV and $V$ show excellent growth development and concurrent suppression of competitive vegetation.

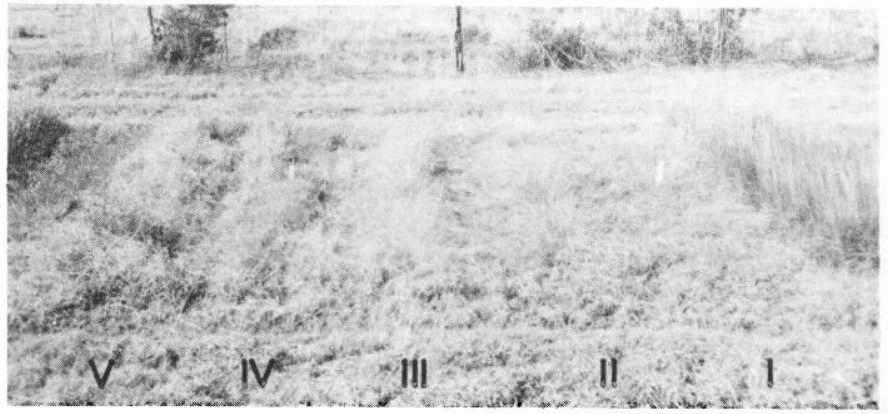

Fig. 3. Florida threeawn response to varied utilization. Treatment I plants are indistinguishable because of competition and overuse.

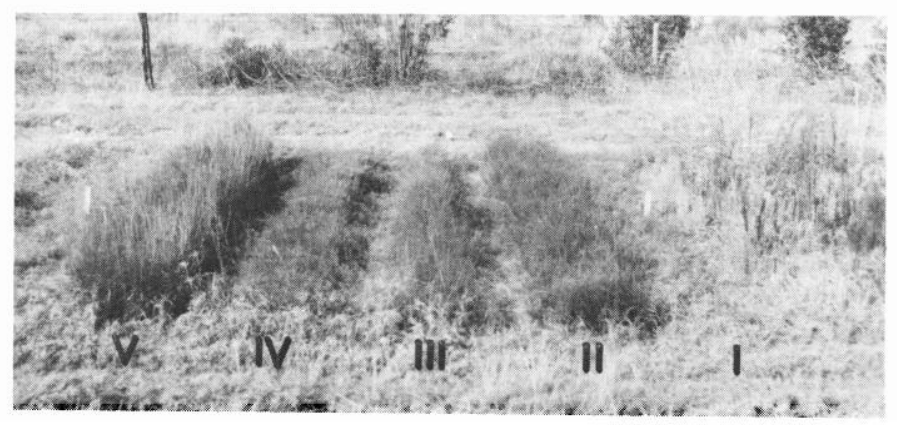

Fig. 2. South Florida bluestem is almost gone because of treatment in the first row but shows good response to other methods of use.

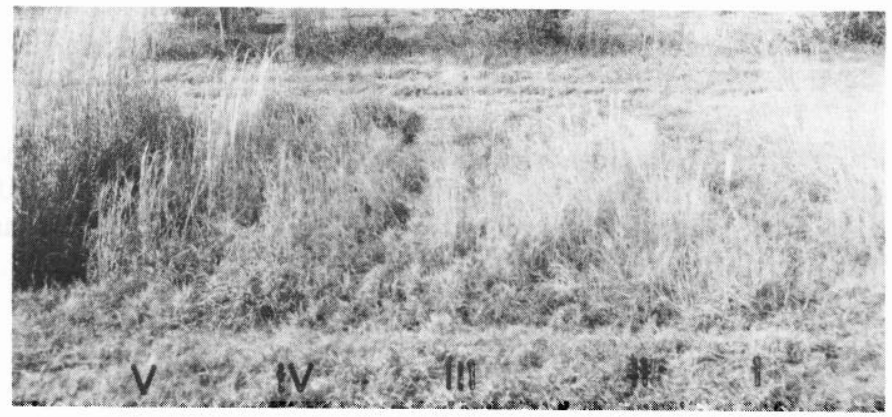

Fig. 4. Broomsedge was suppressed by usage and competing vegetation. Plants of treatment I are not discernable.

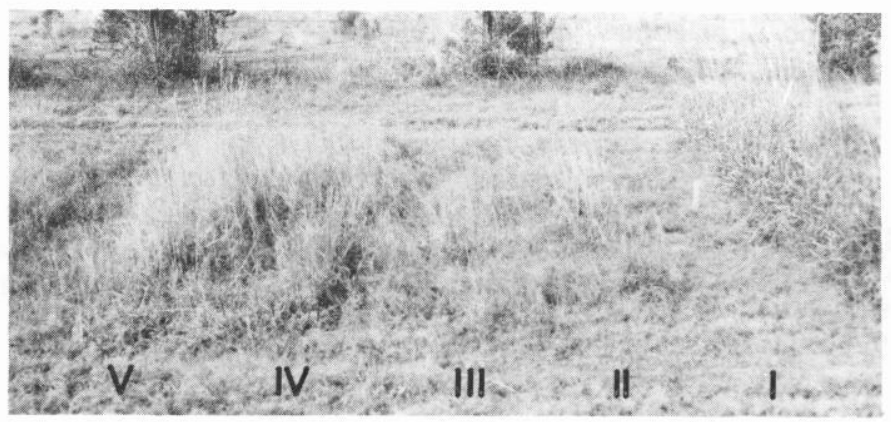

Fig. 5. Chalky bluestem badly depleted by clipping, competition, and time. Plants of treatment I are nearly gone.

broomsedge plants was also affected adversely by time and usage.

Survival of chalky bluestem was very markedly influenced by factors of time and usage as the number of plants surviving to the end of these observations was greatly reduced (Fig. 5). Forage yields of this species were the lowest of the five observed.

At least two of the perennial rhizomatous sod-forming grasses native to Florida and South Florida have a high potential for development and use on managed ranges of Florida. The regional potential for the creeping bluestem exceeds that of the South Florida bluestem because of its much broader range of distribution and its wide adaptation to the acid as well as alkaline soils of the regions in which it is found.
Both creeping bluestem and South Florida bluestem are highly valuable for grazing on ranges and grazable woodlands. Three of the treatment variants compared for use-management have shown that both grasses continue to develop readily, are highly productive, and are compatible with clipping either seasonally or on a deferred rotational basis throughout the year. Excellent vigor and production have been attained by creeping bluestem under $50 \%$ removal of current growth three times yearly, followed by complete removal of top materials during the winter dormant season. Excellent to superior vigor plus consistently high forage yields were obtained by clipping at 50\% during the full-bloom period plus the full use of the available forage in the winter months.
Superior vigor was maintained throughout the period and was accompanied by excellent forage yields with complete removal of top materials during the winter months. Similar results and potential for use were obtained with South Florida bluestem but with reduced vigor and productive capacity.

\section{Literature Cited}

Hitchcock, A. S. 1950. Manual of the Grasses of the United States. U. S. Dep. Agr. Misc. Pub. 200 (2nd Ed. by Agnes Chase). 1,051 p.

Small, J. K. 1903. Flora of the Southeastern United States. Published by the author, New York.

Yarlett, Lewis L., and Robert D. Roush. 1970. Creeping Bluestem (Andropogon stolonifer (Nash) Hitchc.). J. Range Manage. 23:117-122. 